\title{
Penerapan lembaga suluk dalam membentuk nilai-nilai karakter masyarakat
}

\author{
Syafrizal Syafrizal *, Yoyon Suryono \\ Program Studi Pendidikan Luar Sekolah, Program Pascasarjana, Universitas Negeri Yogyakarta, \\ Jalan Colombo No. 1, Karangmalang, 55281, Yogyakarta, Indonesia. \\ * Corresponding Author. Email: syafrizal885@gmail.com \\ Received: 11 October 2018; Revised: 12 November 2018; Accepted: 3 December 2018
}

\begin{abstract}
Abstrak
Suluk adalah pendidikan agama untuk orang-orang di mana pendidikan ini berfokus pada pendekatan Allah SWT melalui kegiatan dzikir. Suluk adalah kegiatan yang bertujuan untuk lebih dekat dengan Kekuatan Allah SWT. Penelitian ini bertujuan untuk mengetahui penerapan lembaga suluk dalam membentuk nilai-nilai karakter masyarakat di Rokan Hulu, Provinsi Riau. Penelitian ini menggunakan tipe kualitatif dengan pendekatan etnografi yaitu pemahaman sudut pandang penduduk pribumi, hubungannya dengan kehidupan, untuk mendapatkan pandangan dunia suluk dengan sampel mursyid (guru utama), wakil mursyid dan pengikut dari suluk. Metode pengumpulan data yang digunakan adalah observasi, wawancara dan dokumentasi di lokasi kegiatan suluk. Hasil penelitian menunjukkan bahwa penerapan lembaga suluk dalam membentuk nilai-nilai karakter masyarakat di Rokan Hulu sangat baik dilihat pada perubahan sikap dan perilaku masyarakat dilihat dari aspek nilai-nilai karakter kejujuran, nilainilai karakter Toleransi, keyakinan nilai karakter , nilai dan nilai karakter kerja keras. tanggung jawab karakter.
\end{abstract}

Kata Kunci: kelembagaan suluk, nilai-nilai karakter, pendidikan suluk

\section{The application of suluk institutions in shaping the character values of the community}

\begin{abstract}
Suluk is a religious education for people where this education focuses on the approach of Allah SWT through dhikr activities. Suluk is an activity that aims to get closer to the Power of Allah SWT. The research aims to find out the application of suluk institutions in shaping the character values of the community in Rokan Hulu, Riau Province. This study uses a qualitative type with an ethnographic approach that is understanding the point of view of the indigenous population, its relationship to life, to get a view of the world of suluk with a sample of murshid (master teacher), vice murshid and followers of suluk. Data collection methods used are observation, interviews and documentation at the location of suluk activities. The results showed that the application of the suluk institution in shaping the values of community characters in Rokan Hulu was very good seen in changes in the attitudes and behavior of the people seen from the aspects of honesty character values, Tolerance character values, confidence character values, hard work character values and values. character responsibility.
\end{abstract}

Keywords: institution of Suluk, character values, education of Suluk

How to Cite: Syafrizal, S., \& Suryono, Y. (2018). Penerapan Lembaga Suluk dalam membentuk nilai-nilai karakter masyarakat. JPPM (Jurnal Pendidikan dan Pemberdayaan Masyarakat), 5(2), 122-127. doi:https://doi.org/10.21831/jppm.v5i2.21543 
JPPM (Jurnal Pendidikan dan Pemberdayaan Masyarakat), 5 (2), 2018 - 123

Syafrizal Syafrizal, Yoyon Suryono

\section{PENDAHULUAN}

Perbuatan prostitusi, minuman keras, pornoaksi, kenakalan remaja dan premanisme semakin berkembang luas di tengah masyarakat kehidupan dan tatanan sosial masyarakat Rokan Hulu. Kondisi di lapangan menunjukkan bahwa remaja pada saat ini sangat memperihatinkan (Leni, 2017; Nurbini, 2011). Banyak ditemukan kasus-kasus kenakalan remaja menjadi masalah yang sampai saat ini belum terpecahkan. Keadaan tersebut harus segera diakhiri dengan berbagai cara dan usaha yang harus dilakukan oleh setiap lapisan masyarakat, termasuk di dalamnya para warga masyarakat. Salah satu usaha yang dapat ditempuh adalah dengan memberikan pendidikan karakter. Pendidikan karakter bertujuan membangun karakter peserta didik agar memiliki karakter bangsa yang kuat, seperti kejujuran, tanggung jawab, beretos kerja tinggi, memiliki keimanan dan ketakwaan yang tinggi sehingga menjadi bermartabat dan mampu menjlankan proses pembelajaran sesuai dengan tujuan pendidikan.

Peraturan Daerah Kabupaten Rokan Hulu, nomor 3 Tahun 2009, Kabupaten Rokan Hulu berjuluk Kabupaten Seribu Suluk dengan menjunjung tinggi nilai-nilai moral, estika, akhlak mulia dan kepribadian luhur bangsa, beriman dan bertakwa kepada tuhan yang maha esa. Suluk bertujuan mengendalikan atau mengontrol pikiran dan suluk adalah jalan batin dan pintu gerbangnya tak lain dari pada hati sendiri (Nurani) (Meilani, 2013).

Lembaga suluk merupakan pendidikan agama bagi masyarakat dimana pendidikan ini menitikberatkan pada pendekatan Allah SWT melalui kegiatan berdzikir (Achmad, 2017). Suluk adalah perjalanan dijalan spritual atau praktik-praktik menuju sang sumber (Nashiruddin, 2018). Suluk merupakan suatu kegiatan yang bertujuan untuk mendekatkan diri kepada sang Kuasa Allah SWT. Suluk sendiri ialah kegiatan, sementara tempat atau wadah untuk belajar agar dapat bersuluk biasa disebut tarekat.

Undang-Undang Nomor 20 Tahun 2003 tentang sistem pendidikan nasional, menjelaskan pendidikan adalah usaha sadar dan terencana untuk mewujudkan suasana belajar dan proses pembelajaran agar peserta didik secara aktif mengembangkan potensi dirinya untuk memiliki kekuatan spritual keagamaan, pengendalian diri, kepribadian, kecerdasan, akhlak mulia, serta keterampilan yang diperlukan dirinya, masyarakat, bangsa, dan Negara (Presiden Republik Indonesia, 2003). Sehingga pada proses pelaksanaan pendidikan haruslah sesuai dengan tujuan pendidikan nasional yaitu: mengembangkan dan membentuk watak serta peradapan bangsa yang bermartabat dalam rangka mencerdaskan keghidupan bangsa, bertujuan untuk pengembangan potensi peserta didik agar menjadi manusia yang beriman dan bertaqwa kepada Tuhan Yang Maha Esa, berakhlak mulia, sehat, berilmu, cakap, kreatif, mandiri, dan menjadi warga negara yang demokratis serta tanggung jawab.

Dalam pendidikan non formal terdapat pendidikan agama, dimana pendidikan agama adalah salah satu pendidikan yang akan membentuk masyarakat menjadi bertakwa terhadap Tuhan Yang Maha Esa sesuai dengan tujuan dari Sistem Pendidikan Nasional. Pendidikan Agama ialah suatu pendidikan yang bertopang pada prinsip-prinsip keagamaan dan tujuannya menuju kepada perealisasian hidup yang sesungguhnya yang semata-mata menuju ridha Ilahi. Pendidikan agama merupakan bagian dari pendidikan seumur hidup, karena pendidikan agama memiliki sifat kodrati, Sehingga pada proses pendidikan sepanjang hayat masyarakat selalu melaksanakan pembelajaran mulai dari sejak lahir sampai ia wafat. Sesuai dengan sabda Rasulullah SAW yang artinya: "Tuntutlah ilmu dari buaian hingga liang lahat” (HR. Bukhori).

Dalam pendidikan karakter disebutkan sebagai pendidikan nilai, pendidikan budi pekerti, pendidikan moral dan pendidikan watak yang bertujuan mengembangkan kemampuan peserta didik untuk memberikan keputusan baik-buruk, memelihara apa yang baik dan mewujudkan kebaikan dalam kehidupan sehari-hari dengan sepenuh hati (Omeri, 2015). Pendidikan karakter saat ini sangat relevan diterapkan dalam lingkungan keluarga dan sekolah sebagai wadah yang berpengaruh besar terhadap pembentukan 
karakter anak. Karakter adalah watak, tabiat, akhlak, atau kepribadian seseorang yang terbentuk dari hasil internalisasi berbagai kebijakan (virtues) yang diyakini dan digunakan sebagai landasan untuk cara pandang, berpikir, bersikap, dan bertindak (Afrizon, Ratnawulan, \& Fauzi, 2012; Dharmawan, 2014).

Berdasarkan uraian tersebut, masalah penelitian ini dapat dirumuskan berdasarkan latar belakang masalah bagaimana penerapan lembaga suluk dalam membentuk nilai-nilai karakter masyarakat di Rokan Hulu dilihat dari aspek yaitu (1) nilai-nilai karakter kejujuran, (2) nilai-nilai karakter toleransi, (3) nilai karakter percaya diri,(4). nilai-nilai karakter kerja keras; dan (5) nilai karakter tanggung jawab.

Penelitian ini bertujuan untuk mengetahui penerapan lembaga suluk dalam membentuk nilai-nilai karakater masyarakat di Rokan Hulu dilihat dari aspek yaitu (1) nilai-nilai karakter kejujuran, (2) nilai-nilai karakter toleransi, (3) nilai karakter percaya diri,(4) nilai-nilai karakter kerja keras. dan (5) nilai karakter tanggung jawab.

Penelitian ini bermanfaat sebagai salah satu usaha untuk memperdalami ilmu yang telah didapat diperkuliahan dan untuk menambah wawasan dalam bidang penelitian dan sebagai pengembangan ilmu diharapkan dapat menjadi salah satu wujud pengembangan ilmu pendidikan yang berkaitan pada pendidikan yang ada di Indonesia.

\section{METODE}

Penelitian yang digunakan dalam penelitian adalah kualitatif dengan jenis pendekatan Etnografi yaitu memahami sudut pandang penduduk asli, hubungannya dengan kehidupan, untuk mendapatkan pandangan mengenai dunianya. Oleh karena itu, peneliti etnografi melibatkan aktivitas belajar mengenai dunia orang yang telah belajar melihat, mendengar, berbicara, berfikir dan bertindak dengan cara yang berbeda, jadi etnografi itu tidak hanya mempelajari masyarakat, tetapi jauh dari itu, Etnogafi belajar dari masyarakat penentuan subjek penelitian terdiri dari mursyid (tuan guru), wakil mursyid dan jamaah pengikut lembaga suluk. Penelitian ini dilakukan di dilakukan di Lembaga Suluk yang beralamat di Jalan Jenderal Sudirman, Kecamatan Tambusai Kabupaten Rokan Hulu Provinsi Riau. Subjek penelitian sebagai informan terdiri dari mursyid (tuan guru), wakil mursyid dan jamaah pengikut lembaga suluk yakni orang-orang yang karena posisinya memiliki pengetahuan, pengalaman dan informasi yang dapat dipertanggungjawabkan menge-nai Penerapan Lembaga Suluk dalam membentuk nilai-nilai karakter masyarakat di Rokan Hulu Provinsi Riau.

Teknik analisi data yang digunakan dalam penelitian ini adalah analisis data kualitatif dilakukan dalam beberapa langkah dengan proses pengumpulan data, interpretasi, dan pelaporan hasil secara serentak dan bersama-sama Untuk mendapatkan hasil yang akurat dan baik.

Teknik pengumpulan data yang digunakan adalah dengan analisis dokumen, observasi, dan wawancara. Teknik dan cara ini diperlukan unntuk mengumpulkan dan mengolah data yang didapat dari lapangan sehingga diharapkan penelitian ini berjalan dengan lancer dan sistematis. Dalam penelitian ini metode pengumpulan data menggunakan metode observasi, wawancara terdiri dari mursyid (tuan guru), wakil mursyid, jamaah pengikut lembaga suluk dan melakukan talaah dokumentasi.

\section{HASIL DAN PEMBAHASAN}

\section{Penerapan Nilai-Nilai Karakter Kejujuran}

Berkenaan dengan hal tersebut, hasil talaah dokumen tentang apakah jamaah melakukan Ibadah Sholat sesuai jadwal dan aturan tanpa diingatkan, (cacatan dan jadwal Sholat 5 Waktu) maka di peroleh data bahwa jamaah suluk secara teratur dan disiplin melakukan ibadah sholat 5 waktu secara berjamaah sesuai dengan jadwal dan aturan yang ada. Selain itu, berdasarkan catatan mursyid, bahwa jamaah melakukan sholat sunat baik siang hari maupun malam hari sesuai dengan jadwal dan keinginan jamaah. Kegiatan tersebut dapat memperkuat rasa persahabatan antar jamaah berdasarkan kegiatan yang jamaah lakukan secara jujur dan disiplin dalam membentuk prilaku relegius. Seterusnya, berdasarkan pengamatan diper- 
oleh bahwa jamaah berbondong-berbondong menuju mushola/surau ketika panggilan sholat (azan) tiba. Mereka pun melakukan sholat sunat, baik sebelum sholat wajib maupun setelah sholat wajib. Ketika pengamatan dilakukan terlihat jelas prilaku kejujuran, religius dan disiplin di lakukan jamaah suluk sesama mereka maupun dengan Tuan Guru suluk.

Nilai karakter kejujuran merupakan prilaku yang didasarkan kepada upaya untuk menjadi diri mereka sendiri sebagai orang yang selalu dapat di percaya, karena jujur dalam perkataan, tindakan dan perbuatan, mempunya prilaku tertib, patuh terhadap berbagai ketentuan dan ajaran agama yang dianutnya, toleran dalam hidup bermasyarakat, dan hidup rukun dalam masyarakat yang heterogen. Hasil demikian itu adalah sebagai bentuk nilai karakter kejujuran yang dapat meningkatkan harkat dan martabat manusia dalam kehidupan secara bersama dan bermasyarakat, yang dilandasi dengan berperilaku jujur, relegius, disiplin dan bersahabat.

\section{Penerapan Nilai-Nilai Karakter Toleransi}

Hasil observasi tentang bagaimana hubungan silahturahmi antara jamaah dengan jamaah lainnya. Maka diperoleh hubungan sesama jamaah berjalan dengan sangat baik, karena setiap jamaah yang mengikuti suluk ini sangat toleransi, sehingga hubungan silautrahmi sangat baik dan tidak ada membeda-bedakan sesama jamaah karena mereka mempunyai satu tujuan, yaitu memeprbaiki akhlak dan prilaku meskipun mereka datang untuk bersuluk dari diri mereka sendiri dengan tidak ada pemaksaan dari pihak mana pun. Sebab itulah, maka jamaah akan merasa senang terhadap apa yangjamaah ikut itu, karena memang panggilan hati untuk berserah diri pada Sang Khalik Yang Maha Kuasa. Nilai karakter toleran digambarkan dengan prilaku yang didasarkan kepada upaya yang menjadikan dirinya sebagai orang yang selalu bersikap sesuai dengan tindakan serta menghargai perbedaan agama, suku, etnis, pendapat, sikap, dan tindakan orang lain yang berbeda dari dirinya dalam masyarakat, selalu ingin memberi bantuan pada orang lain dan membantu masyarakat yang membutuhkan dengan pikiran dan tindakan kesamaan hak dan kewajiban dirinya dan orang lain, selalu berupaya mencegah kerusakan pada lingkungan alam, dan mengembangkan upayaupaya untuk memperbaiki kerusakan alam yang sudah terjadi adalah bentuk nilai karakter toleransi yang dapat meningkatkan harkat dan martabat manusia, dengan didasari sikap toleran,peduli sosial,demokratis dan peduli lingkungan.

\section{Penerapan Nilai-Nilai Karakter Percaya Diri}

Hasil observasi dan wawancara, terhadap bagaiamana keberanian jamaah untuk bertanya dalam forum kajian suluk, dan jamaah tidak merasa sungkan, atau percaya diri untuk bertanya karena jamaah memang saling tidak tahu serta memberi tahu. Tentang bagaiamana keberanian jamaah untuk bertanya dalam forum kajian suluk informan 1 (SM), menjelaskan bahwa keberanian jamaah itu saat kajian tentang suluk kita buka diskusi kecil dan saling terbuka untuk jamaah untuk saling bertanya dan tidak ada pilih kasih dalam mengikuti semua kegiatan kajian suluk. Keadaan ini di benarkan oleh jamaah suluk (informan 4/Tr), yang menyatakan bahwa ia akan bertanya secara langsung jika tidak tahu atau belum mengerti, karena ia harus mampu menjalani kajian tentang suluk dalam kehidupan bermasyarakat dan siap untuk berdakwah untuk masyarakat di lingkungan tempat tinggalnya.

Nilai karakter percaya diri terdapat pada prilaku yang didasarkan kepada upaya menjadi diri sendiri sebagai orang yang selalu bersikap dan berperilaku yang tidak mudah tergantung pada orang lain dalam menyelesaikan tugas-tugas, berpikir dan melakukan sesuatu untuk menghasilkan cara atau hasil baru dari sesuatu yang telah dimiliki dengan diikuti oleh kebiasaan menyediakan waktu untuk membaca yang memberikan kebajikan bagi dirinya merupakan bentuk nilai karakter percaya diri yang dapat meningkatkan harkat dan martabat manusia, dengan dilandasi sikap percaya diri,mandiri dalam kehidupan, kreatif dan gemar membaca dalam mengembangkan dirinya.

\section{Penerapan Nilai-Nilai Karakter Kerja Keras}


Penerapan lembaga suluk dalam membentuk nilai-nilai karakter masyarakat Rokan Hulu Provinsi Riau, khususnya nilai karakter Kerja Keras, berdasarkan observasi dan wawancara tentang bagaiaman jamaah berlatih dalam menghafal surah, ditemukan bahwa jamaah selalu menghafal dan mengulang hafalan sebelum masuknya waktu sholat, karena waktu itu yang paling tepat agar tidak mudah lupa. Selanjutnya, (informan 1/SM) menjelaskan bahwa kegiatan penyampaian materi suluk biasanya setelah sholat 5 waktu, saat itulah jamaah menghafal ayat-ayat suci Alquran dan zikir, dan ini di benarkan oleh jamaah (informan 3/ZL) yang menyatakan bahwa ia menghafal ayat-ayat setelah sholat 5 waktu, supaya khusyuk untuk memperdalam ilmu suluk agar bersuluknya berjalan seacara baik dan khusyuk.

Nilai karakter kerja keras merupakan prilaku yang didasarkan kepada upaya yang menjadi diri sendiri sebagai orang yang selalu melakukan tindakan dengan menunjukkan perilaku tertib dan patuh pada berbagai ketentuan dan peraturan yang mendorong dirinya untuk menghasilkan sesuatu yang berguna bagi masyarakat, dan mengakui, serta menghormati keberhasilan orang lain yang selalu berupaya untuk mengetahui lebih mendalam dan meluas dari sesuatu yang dipelajarinya, dilihat, dan didengar adalah bentuk nilai karakter kerja keras yang dapat meningkatkan harkat dan martabat manusia, dengan diperkuat melalui kerja keras, menghargai prestasi dan selalu ingin tahu tentang sesuatu yang berguna bagi kehidupannya.

\section{Penerapan Nilai-Nilai Karakter Tanggung Jawab}

Hasil penelitian ini mendapatkan tentang bagaimana jamaah melaksanakan kewajibannya sebagai jamaah suluk, (informan 1//SM) menjelaskan bahwa jamaah yang bertanggung jawab biasanya melaksanakan kewajibannya sebagai jamaah seperti sholat, baca Alquran dan kajian tentang suluk. Temuan ini dibenarkan oleh jamaah (informan 3/ZL) denan menyatakan bahwa setiap mau bersuluk maka siap melaksanakan kewajiban dan peraturan yang telah di buatagar bersuluknya berjalan seacara baik dan khusyuk. Sedangkan berdasarkan observasi dan waancara tentang bagaimana jamaah melaksanakan kewajibannya sebagai jamaah suluk, ditemukan pula bahwa jamaah selalu melaksankan kewajiban sebagai jamaah suluk baik sholat wajib maupun sholat sunat dan hal yang perlu dilaksanakan adalah tanggung jawab setiap jamaah yang berada di pemondokan selama kegiatan suluk berlangsung.

Nilai karakter tanggung jawab merupakan prilaku yang didasarkan kepada upaya yang menjadi dirinya sebagai orang yang selalu bersikap dan berperilaku possitif dalam melaksanakan tugas dan kewajibannya, terhadap diri sendiri, masyarakat, lingkungan (alam, sosial dan budaya), negara dan Tuhan Yang Maha Esa, mendorong dirinya untuk menghasilkan sesuatu yang berguna bagi masyarakat, dan mengakui, serta menghormati keberhasilan orang lain dan berwawasan yang menempatkan kepentingan bangsa dan negara di atas kepentingan diri dan kelompoknya adalah bentuk nilai karakter tanggung jawab yang dapat meningkatkan harkat dan martabat manusia, dengan dukungan kuat serta mampu mengemban tanggung jawab,cinta damai dan cinta tanah air.

\section{SIMPULAN}

Penerapan lembaga suluk dalam membentuk nilai-nilai karakter masyarakat Rokan Hulu Provinsi Riau, peserta suluk dianjurkan mengingat perbuatan buruk yang pernah dilakukannya serta meningkatkan penghayatan untuk menambah ketaqwaan. Ibadah ini juga menjaga para pesertanya agar menjauhi perbuatan maksiat dan menyegarkan kembali pikirannya dengan tujuan menambahkan kedekatan diri dengan sang Khaliq, khususnya menerapkan nilai karakter kejujuran, nilai karakter Toleransi, nilai karakter percaya diri, nilai karakter kerja keras dan nilai karakter Tanggung Jawab, berdasarkan penyajian dan analisis data, maka dapat disimpulkan bahwa prilaku yang didasarkan kepada upaya yang menjadi dirinya sebagai orang yang selalu bersikap dan perilaku seseorang untuk melaksanakan tugas dan kewajibannya, yang seharusnya dia lakukan, terhadap diri sendiri, masyarakat, lingkungan (alam, sosial dan budaya), negara dan Tuhan Yang Maha Esa, mendorong diri- 
JPPM (Jurnal Pendidikan dan Pemberdayaan Masyarakat), 5 (2), 2018 - 127

Syafrizal Syafrizal, Yoyon Suryono

nya untuk menghasilkan sesuatu yang berguna bagi masyarakat, dan mengakui, serta menghormati keberhasilan orang lain dan berwawasan yang menempatkan kepentingan bangsa dan negara di atas kepentingan diri dan kelompoknya adalah bentuk nilai karakter yang meningkatkan harkat dan martabat manusia. Apa bila nilai karakter sudah menjadi milik seseorang jamah suluk atau sudah menjadi karakter diri mereka, maka ia senantiasa mampu mengemban tanggung jawab, cinta damai dan cinta tanah air.

\section{DAFTAR PUSTAKA}

Achmad, S. S. (2017). Pendidikan tarekat di Surau Qawiyyul Amin Kabupaten Rokan Hulu. Jurnal Online Mahasiswa (JOM) Bidang Keguruan dan Ilmu Pendidikan, 4(2), 1-7.

Afrizon, R., Ratnawulan, R., \& Fauzi, A. (2012). Peningkatan perilaku berkarakter dan keterampilan berpikir kritis siswa kelas IX MTsN model padang pada mata pelajaran IPA-fisika menggunakan model problem-based instruction. Jurnal Penelitian Pembelajaran Fisika, $1(1)$.

Dharmawan, N. S. (2014). Implementasi pendidikan karakter bangsa Pada mahasiswa di perguruan tinggi. Makalah dipresentasikan pada Pembinaan Pendidikan Karakter bagi Mahasiswa PTS di Lingkungan Kopertis Wilayah VIII, Universitas Udayana Denpasar.

Leni, N. (2017). Kenakalan remaja dalam perspektif antropologi. KONSELI: Jurnal Bimbingan dan Konseling (EJournal), 4(1), 23-34.

Nurbini, N. (2011). Bahasa dakwah untuk kalangan remaja terpelajar. Jurnal Dakwah, 12(1), 117-135.

Meilani, E. (2013). Hubungan sosial dalam Suluk Thariqat Naksyabandiyah di Kelurahan Kota Lama Kecamatan Kunto Darussalam Kabupaten Rokan Hulu. Universitas Riau

Nashiruddin, N. (2018). Education tarekat perspective $\mathrm{KH}$. Ahmad Asrori AlIshaqi and its relevance on national educational objectives. Jurnal Pengetahuan tentang Ilmu Dan Hikmah, 3(1), 31-58.

Omeri, N. (2015). Pentingnya pendidikan karakter dalam dunia pendidikan. Manajer Pendidikan, 9(3). 